\title{
The Effects of Online Learning on Students' Performance: A Comparison between UK and Jordanian Universities
}

\author{
https://doi.org/10.3991/ijet.v16i20.24131 \\ Husam Yaseen $\left.{ }^{\bowtie}\right)$, Anas Ratib Alsoud, Muhmmad Nofal, Omar Abdeljaber, \\ Ahmad Samed Al-Adwan \\ Al-Ahliyya Amman University, Amman, Jordan \\ yaseen.heammanu.edu.jo
}

\begin{abstract}
The Covid-19 pandemic has spread across the globe, causing educational institutions to shut down. As a result, classes have been held online. This study investigated the impact of online learning on student performance by comparing the effect in Jordan and the UK. Both countries have been reported to have high technological competency, but are known to have varying sociodemographic structures. Surveys were conducted on undergraduate students from both countries, $(\mathrm{N}=780)$ to analyse students' perceptions of online learning, self-perceptions of academic capabilities, and faculty performance during online learning. Semi-structured interviews were conducted with professors from both countries $(\mathrm{N}=8)$. The findings indicate that both Jordan and the UK have been very similarly affected in terms of student performance, with major challenges being in communication, technological competency, access to hardware for taking online classes, absenteeism, and drop-outs. Some benefits to student performance were identified as having access to recorded lectures, having more access to faculties through e-mail, and extended office hours. Ethical implications were not commented on. Privacy concerns were largely voiced by faculties.
\end{abstract}

Keywords—online learning, student performance, COVID-19, UK, Jordan

\section{Introduction}

Covid-19 is a global pandemic caused by the SARS-CoV-2 coronavirus that has implemented lockdowns in several countries around the world. Covid-19 was deemed to be a global pandemic by the World Health Organisation on 11 March 2020 [1]. Due to the pandemic, the UK went into lockdown on 23 March 2020 [2] and Jordan went into lockdown on 19 March 2020 [3]. As a result, educational institutions in both Jordan and the UK were effectively shut down, and classes were conducted online when possible.

While online classes have been in existence since the late 1990s, these classes were a choice rather than being the only option. Thus, students who are not capable of having online classes, or students who prefer to attend classes on-campus are not in the same situation as those being given a choice. Rather, students needing to continue classes 
online due to Covid-19 have had to adopt it as an emergency response. This has raised concerns among academics, researchers, and education institutions worldwide [4] taking several factors into consideration such as internet connectivity, technological competence, impact on workload, privacy concerns, socioeconomic factors, communication, academic discourse, and the education environment. Studies so far on the impact of online learning on student performance have focused on a country-specific basis, but a comparative study has not yet been conducted. This study compares the impact of online learning on student performance between Jordan and the UK, in order to understand whether there exists a difference on the nature of the impact on student performance based on country.

The study has examined the Covid-19 history, lockdown implementations in the UK and Jordan, and considered various factors including internet connectivity and hardware capability. Previous research has suggested that students in the UK have good access to technology and have overall high technological competence [5]. In Jordan, technological competencies in university students were also observed to be high [6]. However, these countries have different sociodemographic structures. In order to better understand how the shift to online learning has affected these two different countries, it was important to conduct a study, as such a comparative study has not yet been conducted in light of the Covid-19 pandemic. This paper considers the following aim: To identify and analyse the varying nature of impact on education that has been caused due to the transition to online learning brought about by lockdowns due to the Covid-19 pandemic.

\section{Literature review}

Most studies on the impact of online learning have seen a surge in recent years because of the outbreak of the SARS-CoV-2 virus that forced universities in both the UK and Jordan to shut down. Similar conditions were faced in several countries around the world. [7] made the critical observation that the online learning that has seen a surge due to the Covid-19 outbreak is better categorised as an emergency response action, rather than what online learning ideally should be. Ideally, online learning should be an alternative option to traditional learning, made possible by digitalisation, to offer education to those who need distance education made available to them [8]. The pedagogical response to Covid-19 induced lockdowns has forced online learning to become the accepted form of teaching, making education available to a large portion of the public. However, face-to-face interactions, which are an essential part of the learning process [9], are inherently absent in online classes.

The challenges faced during the online learning phase are the factors that are expected to hinder the learning process. Technology is a major cause for concern as students with outdated devices may not be able to download newer software that demands a higher computer specification, and therefore their learning process is impeded [7]. Socioeconomic factors play a significant part in the learning process. Students with low socioeconomic status rely on the hardware and software provided by the institutions in 
order to comprehend and complete academic tasks [10]. With the forced online platform, students who do not own the required hardware and software fall behind. Also, statistically, students from low socioeconomic backgrounds have a lower chance of having an active internet connection in their household [11-26-27].

Digital competence is a required skill when classes are conducted online. This refers to students' and teachers' abilities to utilise a digital setting, such as using the graphical user interface, understanding audio-video settings, and compiling their assignments in the necessary software. [12] stated that higher education students can significantly lag behind if their digital competence is not able to cope with the demands of the fast-paced online learning environment.

Assessment and supervision present additional challenges for instructors. The question patterns for online exams are different than traditional classroom settings, as outlined by Osterlind [13]. However, a fully online learning environment makes it challenging for supervisors to assess whether there has been any form of academic misconduct [14]. The requirement for assessments and supervision to be online also means additional training requirements for the teachers. This adds to the workload, and according to [15], heavy workloads cause mental stress and induce additional financial and time costs. Furthermore, with communication being strictly online all messages, announcements, and notifications, both inside and outside the classroom, are conducted via email, or a combination of email and electronic learning management systems. The sudden influx of messages makes it difficult for both students and teachers to distinguish between relevant, irrelevant, and high priority messages [7].

The effect of online learning on student performance also varies from one university to another. [24-16] emphasised that the curriculums of social sciences and humanities courses are expected to be less affected by the shift to an online platform, compared to university curriculums of engineering, sciences, and medical sciences, which require a more hands-on approach. [17] noted that virtual laboratories for STEM curriculums in online learning environments do not adequately prepare students for handling instruments properly. One of the main concerns of online education is getting access to the live lectures online. The success of an academic institution's online learning initiative relies on the availability of proper hardware such as a personal computer, or a smartphone, with an active internet connection [18]. In developed nations such as the USA, taking Georgia as an example, $79.3 \%$ of households have an active internet connection. According to the findings of [18], universities used Google Suite Education and an electronic learning management system to conduct lectures online.

In developing nations such as India, a significant portion of students who were able to access online classes used their smartphones [19]. However, students suffered when trying to access online lectures from remote areas where connectivity issues are still prevalent. In India, a multitude of platforms were used for online learning, for example, YouTube, Zoom, and Google Meet, and were facilitated by messaging applications such as WhatsApp, Skype, electronic learning management systems, and Google classrooms. Online learning, however, does present some opportunities in the form of increased flexibility, being more interactive, and allowing students to study at their own pace [7-25]. The biggest opportunity, however, is that students still have the option to continue to learn. Educational institutions have the option to provide students with the 
option that at least partially allows them to deliver their obligation of continued education [20]. The increased investment in online learning also enabled further opportunities for academic institutions.

Research innovation is a huge opportunity due to the requirement for online learning during the time of COVID-19. Research could focus on developing frameworks for digitisation processes, digitisation adoptions, improving online learning to allow individual attention to students, and also rethinking the learning process [7]. It is also an opportunity for education institutions to strengthen their IT facilities which can further be used for continuity of business [21]. A study by [5] explored the digital disruptions faced by universities in the United Kingdom due to the Covid-19 lockdown and the shift to online lectures. With a sample size of 1148 , this study qualitatively explored what academics in universities across the UK thought would be the main concerns due to the shift to online learning. The study revealed that preparedness and confidence were both relatively high for academics in the computer science department and the education department. On the other hand, academics in the social sciences departments felt unprepared and unconfident. Similar observations were made regarding academics' thoughts on support from institutions, where computer science and education departments reported overall agreement that their institutions were supportive in the transition to taking online classes. However, social sciences and arts departments were less likely to agree to the statement. A large portion of academics in universities in the UK agreed that they had access to support for online learning, but were concerned about the increased workload, and the lack of interactions that took away the personal aspect of teaching. This threatens the mental health of not only the academics, but also the students.

\section{$3 \quad$ Research methodology}

This study applied a mixed research methodology. Both quantitative and qualitative processes were used to analyse student performance in an online learning environment. The quantitative research methodology was used to numerically analyse student performance. The quantitative part of this study involved an online survey. The survey was divided into four sections. Section A: Online Learning Perception contained 25 questions about how the students felt about the online learning environment. Section B: Student Self-Perception comprised ten questions about how the students perceived their own academic abilities and course load management. Section C: Course/Instructor Evaluation had six questions about how the students felt about their course instructors' performances during online learning. Section D: Demographics contained five questions about students' demographic details and their Grade Point Average. Student performance was determined by the Grade Point Average (GPA) during an ongoing semester. With the exception of the questions in Section D, all other questions had to be answered using a 5-point Likert Scale where 1: Strongly Disagree; 2: Disagree; 3: Neutral; 4: Agree; 5: Strongly Agree. After the survey, a qualitative analysis was conducted with course instructors. 
The qualitative research methodology was used to obtain further information about the online learning environment. This involved a semi-structured interview of the course instructors, faculty, administrators, and department heads. The interview questions were open ended but based on the students' responses during the survey. The nature of the questions were similar to the survey questions. Thus, the questions were closely based on the interviewees' perceptions of the online learning environment, students' performance during online learning, their self-perception of their abilities to conduct classes during online learning, and the overall impact on GPA due to online learning.

\subsection{Research Population and Sample Size}

The research population consisted of undergraduate students in the UK and Jordan who have taken full-time online classes during the Spring semester of 2021. In the UK, the number of full-time undergraduate students in 2019 was 1.8 million [22], and in Jordan in 2015 this was 267,000 [23]. These are the most recent statistics available regarding student enrolment in the UK and Jordan. The population size was, therefore, two million full-time undergraduate students in the UK and Jordan combined.

The sample population that would accurately represent student responses regarding the online learning environment was based on a confidence level of $95 \%$ and a confidence interval of five. The sample population was divided to accurately represent both the UK and Jordanian students. To achieve the desired confidence level and interval for the UK, 384 responses were required. To achieve the desired confidence level and interval for Jordan, an additional 384 responses were required. Therefore, in total, 768 responses were required. For semi-structured interviews, there was no fixed number of responses, but interviews were taken until data saturation was observed.

\subsection{Data collection}

The survey data was collected online by presenting a URL to students in universities in the UK and Jordan. The survey consisted of 41 questions and required around 20 minutes to complete. The interview had no fixed number of questions due to its semistructured format. Since universities do not have the same semester duration, the online survey was conducted for an extended period of time throughout the months of April and May 2021. This ensured that all the students had completed their Spring semesters to fully answer the survey questions and the university faculties, department heads and administrators were able to provide interview answers based on their experience in the most recent semester. In total, 780 surveys were collected at the end of May 2021 and eight interviews were conducted. Of these, 340 surveys were from the UK, and 440 surveys were from Jordan. From the UK, four interviews were conducted, and in Jordan, four interviews were conducted. 
Paper-The Effects of Online Learning on Students' Performance: A Comparison between UK and...

\subsection{Data analysis}

The quantitative data was analysed using SPSS software. The survey results were extracted in a csv format and the data processed using SPSS. First, incomplete survey submissions were discarded. Next, each of the questions were assigned to a descriptive variable in SPSS. The survey questions were structured such that the Likert Scale response reflected a greater degree of positive online learning environment for the students. This was done to ensure that all the questions were scaled appropriately, and that none of the responses would need to be processed to reverse the order of the response. Regression analyses were then performed to find correlations in various regression models. The first model analysed the correlation between online learning perception, the dependent variable, and student self-perception, the independent variable. The second model analysed the correlation between online learning perception, the dependent variable, and course/instructor evaluation, the independent variable. The control variable for both models was students' GPA.

The interview questions were analysed using NVivo software. The analysis process was iterative with each iteration serving the purpose of identifying themes. Each of the themes were then assigned a name, also called a code. Through multiple iterations of reviewing the interview transcripts, descriptions of the codes, the links in between themes, and patterns were recognised from the responses.

\section{$4 \quad$ Results}

\subsection{Survey results}

The majority of survey respondents were aged between 18 and 25 years old. The largest number of responses were from junior year students, followed by seniors, sophomores, and freshmen. All the students who responded to the survey in both Jordan and the UK were taking at least nine credit courses. In both Jordan and the UK, the majority of students had a current Grade Point Average of 3.00-3.49. Table 1. illustrates the survey's demographic information.

The common observations for both countries are that the majority of students either "Agree" or "Strongly Agree" that in an online learning setting they are able to ask questions, take good class notes, prepare well for exams, manage time efficiently, spend time with family, do the required reading tasks, research term papers, talk to their professors, and find the time to study. The majority of students feel "Neutral" that in an online learning setting they are able to study, keep up with required reading, submit papers on time, handle multiple tests in the same week, manage both school and work, improve their reading and writing skills, get help and information at school, talk to university staff, understand textbooks and lectures, participate in class discussions/guiding questions, and understand university regulations.

The majority of students either "Disagree" or "Strongly Disagree" that in an online learning setting they are able to study effectively, understand their professors in the online learning setting, write term papers with confidence, socialise with their peers, do 
well in exams, achieve the grades they want, and do well in their toughest classes. Regarding student self-perception, the majority of the students responded that they get their assignments done ahead of time, consider being a part of the class to be important, consider classroom discussions helpful to them, feel comfortable taking part in class discussions, prefer having their professors explain assignment instructions to them, and consider frequent interactions with instructors is part of doing well in a course. However, most students do not complete all the assigned reading, do not participate in group studies, or read the online reading materials by printing them out, but rather prefer to read them on the computer.

Table 1. Demographic Information

\begin{tabular}{|c|c|c|c|}
\hline \multicolumn{4}{|l|}{ Country } \\
\hline Jordan & \multicolumn{3}{|c|}{$\mathrm{N}=440$} \\
\hline UK & \multicolumn{3}{|c|}{$\mathrm{N}=340$} \\
\hline Total & \multicolumn{3}{|c|}{780} \\
\hline \multicolumn{4}{|l|}{ Age } \\
\hline Mean & Median & Max & Min \\
\hline 23.2 & 20 & 25 & 18 \\
\hline \multicolumn{4}{|l|}{ Gender } \\
\hline & Total & Jordan & UK \\
\hline Male & 355 & 207 & 148 \\
\hline Female & 425 & 233 & 192 \\
\hline \multicolumn{4}{|c|}{ Year of Education } \\
\hline & Total & Jordan & UK \\
\hline Freshman & 234 & 132 & 102 \\
\hline Sophomore & 195 & 110 & 85 \\
\hline Junior & 179 & 101 & 78 \\
\hline Senior & 172 & 96 & 76 \\
\hline \multicolumn{4}{|c|}{ Credit Hours } \\
\hline Mean & Median & Max & Min \\
\hline 10.5 & 12 & 15 & 9 \\
\hline
\end{tabular}

Course instructors presented the course expectations very clearly, but were unable to provide prompt feedback on assignments. They were actively involved in course discussions and made themselves accessible to students. Students all strongly agreed that interactions with instructors were very helpful in understanding course materials. However, students were not always clear on due dates for assignments and exams.

There was a statistically significant $(\mathrm{P}<0.05)$ positive correlation between online learning perception and student self-perception. A statistically significant $(\mathrm{P}<0.05)$ positive correlation was also found between online learning perception and course instructor evaluation. Finally, a statistically significant $(\mathrm{P}<0.05)$ positive correlation was also found between Grade Point Average and online learning perception. There was no correlation established between age and online learning perception, or student self-percep- 
Paper-The Effects of Online Learning on Students' Performance: A Comparison between UK and...

tion. There was also no observable correlation between academic year and online learning perception, or student self-perception. Table 2. demonstrates the correlations findings.

Table 2. Correlations

\begin{tabular}{|l|c|c|}
\hline Item & $\begin{array}{c}\text { Correlation } \\
\text { Coefficient } \boldsymbol{\beta}\end{array}$ & P-Value \\
\hline Correlation between online learning perception and student self-perception & $0.356^{*}$ & 0.01 \\
\hline Correlation between online learning perception and course instructor evaluation & $0.218^{*}$ & 0.01 \\
\hline Correlation between online learning perception and Grade Point Average & $0.308^{*}$ & 0.01 \\
\hline Correlation between online learning perception and age & 0.005 & 0.015 \\
\hline Correlation between age and student self-perception & 0.018 & 0.08 \\
\hline Correlation between academic year and online learning perception & 0.153 & 0.08 \\
\hline Correlation between academic year and student self-perception & 0.213 & 0.08 \\
\hline
\end{tabular}

* Statistically Significant

\subsection{Interview results}

The semi-structured interviews were conducted with eight professors, four from universities in Jordan, and four from universities in the UK. Through thematic coding, common patterns started to appear in the transcript, and a list of themes began to emerge; these themes were collected and are presented in the following table (see Table 3. ).

Table 3. Interviews Emerging Themes

\begin{tabular}{|l|c|c|c|}
\hline $\begin{array}{l}\text { Technological } \\
\text { Competency }\end{array}$ & $\begin{array}{c}\text { Increased } \\
\text { Workload }\end{array}$ & $\begin{array}{c}\text { Work-Life } \\
\text { Balance }\end{array}$ & $\begin{array}{c}\text { Privacy } \\
\text { Concerns }\end{array}$ \\
\hline Communication & Academic Performance & Ethical Considerations & Opportunity for Reform \\
\hline
\end{tabular}

Technological competency. The most common theme from all the responses were concerns about the technological competencies of faculty and students. The interviewees stated that they were not initially experienced in conducting lectures online, and did not know how to navigate around the online lecture tools that were suggested by the universities. There was a learning curve as faculties had to familiarise themselves with the user interface and presenting source materials to students. Illustrations were highlighted as being particularly difficult to display in an online environment, as those without tablets and smart-pens were not able to interactively draw on online whiteboards as they were used to doing physically. Mouse and keyboard navigation during online lectures took up time and, therefore, proved to be less efficient. However, technology competence grew among all interviewees, and they felt more comfortable by the end of the first semester of conducting classes online.

Increased workload. An increase in workload was commented as being one of the greatest challenges of the online environment for associate professors in both Jordan and the UK. While previously, lectures sheets were available, which the interviewees 
would refer to while illustrating problems on the physical whiteboard, they now have to create materials in a digital format to share screens during online lectures. It takes time to create files and adjust the subsequent lectures based on current progression. There are also additional tasks after the end of each day to organise, upload, and edit recorded materials so that students are able to refer to them afterwards. One respondent commented that:

"Each lecture needs to be attended to three times. Once before the lecture begins, once during the lecture, and once again when the lecture needs to be uploaded. We also need to change the following day's material based on how much we were able to cover today"

Office hours were also different as the design changed from having an office for student visits to having online consultation hours, based on e-mail appointments.

Work-life balance. As the classes are being conducted from home, there is no time lost to commuting. All the interviewees created an office space in their homes to keep their work and personal lives separate. While the interviewees found more time for family, an emotional toll was expressed by some because of the lack of differentiation between the workplace and their home. One interviewee commented:

"Working where I live is convenient, but it takes away the essence of going to a university campus and conducting classes in an academic setting. It is difficult to disassociate ourselves from our personal lives for long periods of time when that life is going on right in the background."

The interviewees believed that students were also facing the same issues, and it was a joint struggle that everyone has to work through. Regardless, the opportunity allowed for more time with family, and an online environment helped balance work and life better than before.

Privacy concerns. The interviewees expressed concerns for students who did not have the luxury of an isolated environment during online lectures. Thus, their personal lives were on display on camera during video calls, or were heard in the background from their audio feed. One interviewee commented that:

"Nobody should be obligated to show what their personal lives look like. Their private lives belong to them, and everyone has their own personal problems. I am concerned for students' emotional states if their personal lives are on display for everyone to see. I don't make it mandatory for students to have their videos on, and I encourage them to stay muted and communicate through the message boxes if necessary."

Interruptions during lecture hours from online lecture attendants' private lives affected the flow of information during the lectures. Thus, privacy concerns not only affected the emotional states of students, but also the coherence of lectures.

Communication. Communication has been noted as being a great difficulty to overcome for the interviewees as they are not able to read the students' body language in class. According to the interviewees, body language is crucial for feedback to understand whether the class is engaged or not. It is also not possible to communicate properly in lectures where a physical demonstration is necessary for the coursework. In these cases, online videos are helpful, but, according to an interviewee: 
"The interaction that students used to be able to get when a practical demonstration was shown in front of them offered a level of immersion that online platforms are just not able to deliver."

Academic performance. Drop-outs and absenteeism were seen to rise significantly in online environments. When lectures were recorded, the amount of absenteeism was seen to increase. Students who were absent more frequently were seen to perform poorly in assignments and examinations. The overall trend of academic performance among students remained as consistent as if they were in regular class settings. Students who regularly participated in class discussions, guided the discussion, or interacted in the live message boxes were seen to consistently perform well across all courses that the interviewees conducted.

It was commented that some evidently sincere students were affected due to online lectures as their technological competencies were lacking. Thus, deduction of marks due to late submissions were a common observation. Grade scaling was applied in most cases to make it fair for everyone. The interviewees believed that they tried their best to conduct classes online as smoothly as possible and focused on course delivery methods where students would have the most knowledge retention. Thus, recorded online lectures were particularly helpful. Frequent student engagements were common in all courses, but the number of students who frequently communicated were minimal. Students also tend to leave studying the material to the last minute, as was evident from crucial queries in emails sent on the night before an in-class assessment. These emails were often outside of suggested office hours and students struggled to put in the extra effort needed to review recorded materials beforehand.

Ethical considerations. The interviewees commented about an increase in plagiarism, and an increase in the number of replicated solutions across student submissions. However, the interviewees added that since the recorded lectures provided guidelines for solutions, some repetitions were expected. Ethical concerns were voiced among all the interviewees regarding how fair it was that some students were able to continue their education while others had to drop out. While students were informed of hardware support from universities to continue their semester, not everyone availed of it. The interviewees reflected on some students' comments about joining online classes from their smartphones, but the lack of interactive features on a smartphone app compared to the desktop version of the software made it difficult for them to continue at the same pace as the rest of the class. In this case, ethical concerns were raised as these students had to invest an effort which did not make the academic setting a level playing field for everyone.

Opportunity for reform. While online classes were considered a quick response to lockdowns, the interviewees said that this is not a fully sustainable academic setting. It can be, by choice, but not as a requirement. Thus, the interviewees all responded positively to providing online support alongside traditional academic settings, but would not consider online learning as an alternative to on-campus learning. One comment that best summarises all the responses was:

"Flipped models can work, but not an online only learning environment. We already have online classes, but students are given the choice for that. Supplementary materials 
Paper-The Effects of Online Learning on Students' Performance: A Comparison between UK and...

posted online will be a good model for studying. We already have email communications available. So, nothing changes, but we all definitely realise the potential of online tools to help us explain the course materials better."

\section{Discussion}

The results indicate that online learning has affected students in Jordan and the UK similarly. The same problems faced in Jordan are also faced by students in the UK. Students from both countries have experienced drop-outs and increased absenteeism due to technological constraints. Additionally, professors from both Jordan and the UK have commented that online education is recognised as a response to the lockdown rather than as a sustainable platform to exclusively conduct classes online. These are consistent with the findings of [7] who also observed that online classes are a response to the Covid-19 pandemic. The findings also suggest that professors from both Jordan and the UK consider online classes an important alternative for those students who have the capability of availing of them, which agrees with the findings of [8].

Students from both Jordan and the UK have faced similar communication difficulties. Professors from both countries have also commented on feeling a disconnect from students due to needing to communicate online. The lack of body language explains the difficulty of the situation, which is congruent to the findings of [9]. Furthermore, technological competency and access to technology have both been found to be reasons that affect academic performance in students, and the ability to conduct classes with ease. This was also the finding of [7]. Universities in both the UK and Jordan have considered the socioeconomic disparity among students, and have made hardware available to those students in need. Online education has been supported by institutions in some countries before [10] but this is being adopted on a wider scale in both Jordan and the UK now. Consistent with the findings of [11], several professors from both Jordan and the UK have voiced their concerns about not everyone having the same level of access to technology to sustain online classes or having the same digital competency [12].

The concerns raised by [13] were not seen to be a factor regarding online supervision. Thus, the concern about evaluation online has not been raised by any of the interviewees in either Jordan or the UK. Similarly, academic misconduct concerns [14] were also not highlighted by the interviewees, particularly because the mode of online lecture delivery makes replication more likely. Increased workload was suggested to be a common problem in online environments in earlier studies such as that by [15]. Increased workload challenges were also made worse by needing to answer emails. However, the interviewees did not comment on this being an overwhelming difficulty as was suggested by [7]. However, the added workload due to lack of communication is a concern for both Jordan and the UK, which is also consistent with previous suggestions by [16]. Also, similar to [17] who noted that virtual laboratories for STEM curriculums in online learning environments do not adequately prepare students for handling instruments properly, professors from both countries suggested that online videos are not a good replacement for practical demonstrations. 
Similar to the findings regarding the convenience of online education for those who have an active internet connection [18] and access to hardware [19], the level of interaction has increased for a few students. Searching for term papers has also been seen to be a comfortable area for students in both Jordan and the UK. For those students who have the opportunity to continue semesters using an online platform, the dedication to their academic performance reflects that their grade point averages have also remained consistently high. This is in agreement with the findings of [20]. The findings also partially confirm the findings of [5] who commented that some students would display a higher level of confidence and preparedness in online learning. The majority of the students in both Jordan and the UK commented that they felt prepared and confident for online classes.

\section{Conclusion}

The findings of this study indicate that both Jordan and the UK have experienced a similar impact on student performance due to online learning. There have been technological challenges that have hindered communication between students and faculties. The survey of students indicates that those students who have good academic conduct have been able to adapt to the transition to online platforms, but the semi-structured interview of the professors indicated that there have also been cases where academically good students were unable to perform at their best due to not having high technological competence or access to the hardware required to continue performing as well as other students. Absenteeism and drop-outs have also increased for both Jordan and the UK. The frequency of communication through emails between students and faculties has also increased but this has also increased the work-load for both parties. Students and faculties both commented that online learning has affected their work-life balance. This was again observed for both Jordan and the UK.

These findings have been shown to be consistent with previous findings. The findings of this study are therefore important for directing future research. This study is the first of its kind to compare the impact of online learning between two countries. Therefore, this study has its strength in its novelty. However, it is limited in its findings because it explores the nature of the impact, and not its magnitude. Thus, this study should be used by academics to quantify the items explored in the survey and the questionnaires to address this limitation.

\section{$7 \quad$ References}

[1] WHO. (2020, July 30). Rolling updates on coronavirus disease (COVID-19). Retrieved April 24, 2021, from World Health Organisation: https://www.who.int/emergencies/ diseases/novel-coronavirus-2019/events-as-they-happen

[2] Institute for Government UK. (2021, March). Timeline of UK coronavirus lockdowns, March 2020 to March 2021. Retrieved April 24, 2021, from Institute for Government UK: https://www.instituteforgovernment.org.uk/sites/default/files/timeline-lockdown-web.pdf, https://doi.org/10.1093/hepl/9780198825555.003.0003 
Paper-The Effects of Online Learning on Students' Performance: A Comparison between UK and...

[3] HRW. (2020, March 20). Jordan: State of Emergency Declared - Government Promises to Respect Rights in COVID-19 Response. Retrieved April 24, 2021, from Human Rights Watch: https://www.hrw.org/news/2020/03/20/jordan-state-emergency-declared, https:// doi.org/10.1163/2210-7975 hrd-2156-0375

[4] Zheng, B., Lin, C. H., \& Kwon, J. B. (2020). The impact of learner-, instructor-, and courselevel factors on online learning. Computers \& Education, 150, 103851. https://doi.org/10. $\underline{1016 / j . c o m p e d u .2020 .103851}$

[5] Watermeyer, R., Crick, T., Knight, C., \& Goodall, J. (2020). COVID-19 and digital disruption in UK universities: Afflictions and affordances of emergency online migration. Higher Education, 1-19. https://doi.org/10.1007/s10734-020-00561-y

[6] Rajab, L. D., \& Baqain, Z. H. (2005). Use of information and communication technology among dental students at the University of Jordan. Journal of dental education, 69(3), 387398. https://doi.org/10.1002/j.0022-0337.2005.69.3.tb03927.x

[7] Adedoyin, O. B., \& Soykan, E. (2020). Covid-19 pandemic and online learning: the challenges and opportunities. Interactive Learning Environments, 1-13. https://doi.org/10. $\underline{1080 / 10494820.2020 .1813180}$

[8] Means, B., Toyama, Y., Murphy, R., Bakia, M., \& Jones, K. (2009). Evaluation of evidencebased practices in online learning: A meta-analysis and review of online learning studies.

[9] Joshi, O., Chapagain, B., Kharel, G., Poudyal, N. C., Murray, B. D., \& Mehmood, S. R. (2020). Benefits and challenges of online instruction in agriculture and natural resource education. Interactive Learning Environments, 1-12. https://doi.org/10.1080/10494820.2020. 1725896

[10] Demirbilek, M. (2014). The 'digital natives' debate: An investigation of the digital propensities of university students. Eurasia Journal of Mathematics, Science and Technology Education, 10(2), 115-123. https://doi.org/10.12973/eurasia.2014.1021a

[11] Fishbane, L., \& Tomer, A. (2020). As classes move online during COVID-19, what are disconnected students to do. Brookings Institute.

[12] Omotayo, F. O., \& Haliru, A. (2020). Perception of task-technology fit of digital library among undergraduates in selected universities in Nigeria. The Journal of Academic Librarianship, 46(1), 102097. https://doi.org/10.1016/j.acalib.2019.102097

[13] Osterlind, S. (2002). Constructing test items: Vol. 47. Evaluation in education and human services. Dordrecht, the Netherlands: Springer.

[14] Arkorful, V., \& Abaidoo, N. (2015). The role of e-learning, advantages and disadvantages of its adoption in higher education. International Journal of Instructional Technology and Distance Learning, 12(1), 29-42.

[15] Akkoyunlu, B., \& Soylu, M. Y. (2006). A study on students' views on blended learning environment. Turkish Online Journal of Distance Education, 7(3), 43-56.

[16] Leszczyński, P., Charuta, A., Łaziuk, B., Gałązkowski, R., Wejnarski, A., Roszak, M., \& Kołodziejczak, B. (2018). Multimedia and interactivity in distance learning of resuscitation guidelines: a randomised controlled trial. Interactive Learning Environments, 26(2), 151162. https://doi.org/10.1080/10494820.2017.1337035

[17] Iqbal, S., Zang, X., Zhu, Y., Hussain, D., Zhao, J., Gulzar, M. M., \& Rasheed, S. (2015, November). Towards moocs and their role in engineering education. In 2015 7th International Conference on Information Technology in Medicine and Education (ITME) (pp. 705709). IEEE. https://doi.org/10.1109/itme.2015.89

[18] Basilaia, G., \& Kvavadze, D. (2020). Transition to online education in schools during a SARS-CoV-2 coronavirus (COVID-19) pandemic in Georgia. Pedagogical Research, 5(4). https://doi.org/10.29333/pr/7937 
Paper-The Effects of Online Learning on Students' Performance: A Comparison between UK and...

[19] Kapasia, N., Paul, P., Roy, A., Saha, J., Zaveri, A., Mallick, R., ... \& Chouhan, P. (2020). Impact of lockdown on learning status of undergraduate and postgraduate students during COVID-19 pandemic in West Bengal, India. Children and Youth Services Review, 116, 105194. https://doi.org/10.1016/j.childyouth.2020.105194

[20] Wang, C., \& Zha, Q. (2018). Measuring systemic diversity of Chinese universities: a clustering-method approach. Quality \& Quantity, 52(3), 1331-1347. https://doi.org/10.1007/ s11135-017-0524-5

[21] Manfuso, L. G. (2020). How the remote learning pivot could shape Higher Ed IT. EdTech Magazine.

[22] Statista. (2020). Number of students enrolled in higher education in the United Kingdom (UK) from 2012 to 2019. Retrieved March 28, 2021, from Statista: https://bit.ly/3hzElyj

[23] QS. (2017, October 10). Higher education in Jordan: history, present status and future. Retrieved March 28, 2021, from Quacquarelli Symonds: https://bit.ly/3u4oNVx

[24] Al-Adwan, A., Al-Adwan, A., \& Smedley, J. (2013). Exploring students acceptance of elearning using Technology Acceptance Model in Jordanian universities. International Journal of Education and Development using ICT, 9(2).

[25] Al-Adwan, A., \& Smedley, J. (2012). Implementing e-learning in the Jordanian Higher Education System: Factors affecting impact. International Journal of Education and Development using ICT, 8(1).

[26] Al-Adwan, A.S, \& Khdour, N., 2020. Exploring Student Readiness to MOOCs in Jordan: A Structural Equation Modelling Approach. Journal of Information Technology Education: Research, 19, pp.223-242. https://doi.org/10.28945/4542

[27] Al-Adwan, A. S., Al-Madadha, A., \& Zvirzdinaite, Z. (2018). Modeling students' readiness to adopt mobile learning in higher education: An empirical study. International Review of Research in Open and Distributed Learning, 19(1). https://doi.org/10.19173/irrodl. $\underline{\text { v19i1.3256 }}$

\section{Authors}

Dr Husam Yaseeen is the head of E-Business and MIS departments, and an Assistant Prof. of Information systems at Al-Ahliyya Amman University, Jordan. He holds a Ph.D in Information Systems/E-Commerce from The University of Portsmouth, UK. $\mathrm{He}$ is particularly specialized in digital business transformation and development. His research interests include UX, Digital Marketing, e-learning, e-commerce, IOT, cyber security, Cloud Computing.

Anas Ratib Alsoud is an Associate professor in Electronic Business and Commerce department. Anas holds a PhD in Informatics from the University of Reading - UK. Since joining AL-Ahliyya Amman University in 2012, Anas has been involved with studies related to e-business, e-government, and cloud computing in developing countries. He is currently working as the assistant to the president for international accreditation and rankings, director of center of innovation and excellence, and director of teaching and learning center at AL-Ahliyya Amman University.

Muhmmad Nofal is an Assistant Prof. of Management Information systems at AlAhliyya Amman University, Jordan. Dr. Nofal hold a PhD in Information Technology from Universiti Kebangsaan Malaysia. His research interests are ERP system implementations, Digital Marketing, and E-government. 
Omar Abdeljaber is an Assistant Prof in Electronic Business and Commerce department at Al-Ahliyya Amman University, Jordan. Dr. Abdeljaber hold a PhD in Information Systems from Cardiff Metropolitan University, UK. His research interests are E-business implementations, Digital Marketing, and E-Learning.

Ahmad Samed Al-Adwan is the Vice Dean for academic affairs and an Associate Prof. of Electronic Business and Commerce at Al-Ahliyya Amman University, Jordan. He holds a PhD in Management Information Systems Studies/E-business from the University of Wales, UK. His research interests include user acceptance of ICT and information systems, e-learning, m-commerce, e-business, and healthcare information technology.

Article submitted 2021-05-20. Resubmitted 2021-06-25. Final acceptance 2021-06-28. Final version published as submitted by the authors. 